\title{
\begin{tabular}{l|l|l} 
& Jurnal Kependidikan Dasar & Volume. 2 \\
Nomor.1 \\
Tahun.2017
\end{tabular}
}

\section{Komunikasi Orang Tua dan Anak dalam Islam \\ (Tinjauan Pedagogis Komunikasi Nabi Ibrahim dengan Nabi Isma'il dalam Al-Qur'an)}

\author{
Zeni Murtafiati Mizani \\ Dosen Prodi PAI IAIN Ponorogo \\ zenimurtafiatimizani@gmail.com
}

\begin{abstract}
Abstrak
Komunikasi merupakan proses penyampaian suatu pesan dalam bentuk lambang bermakna sebagai pikiran dan perasaan berupa ide, informasi, kepercayaan, harapan, himbauan, dan sebagai panduan yang dilakukan oleh seseorang kepada orang lain. Orang tua dan anak adalah komponen yang paling penting dalam sebuah keluarga. Orang tua memiliki peran penting dalam mendidik anak-anaknya melalui proses komunikasi. Al-Qur'an sebagai sumber pertama dan utama pendidikan Islam memberikan beberapa gambaran kisah tentang komunikasi orang tua dan anak. Salah satu kisah tersebut adalah kisan Nabi Ibrahim dan Nabi Isma'il dalam Q.S. al-Shäffät ayat 102-107. Berdasarkan ayat-ayat dari surat tersebut dapat disimpulkan komunikasi orang tua dan anak (berdasarkan kisah Nabi Ibrahim dan Nabi Ismail) sebagai berikut: 1) Komunikasi yang terjadi adalah komunikasi interaktifdialogis-humanis. Dikatakan interaksional karena komunikasi yang dilakukan tidak sepihak. Nabi Ibrahim dan Nabi Isma'il saling aktif, reflektif dalam memaknai dan menafsirkan pesan dalam mimpi Nabi Ibrahim. Dialogis karena komunikasi tersebut dapat membuka jalur informasi antara Nabi Ibrahim dan Nabi Ismail. Komunikasi dialogis juga membantu untuk melatih berargumentasi, kesabaran, ketangguhan, dan keteguhan untuk patuh kepada Allah dan taat pada orang tua, seperti yang terjadi pada komunikasi Nabi Ibrahim dan Nabi Ismail. Humanis karena Pendidikan Ibrahim terhadap Ismail bertujuan untuk memanusiakan manusia agar patuh kepada Allah; 2) Komunikasi yang dilakukan Nabi Ibrahim dengan Nabi Isma'il memberikan gambaran bahwa Nabi Ibrahim merupakan sosok yang demokratis dan Nabi Isma'il adalah sosok yang patuh. Kedua sifat ini memiliki peran penting dalam kesuksesan sebuah pendidikan; 3) Terdapat dua materi pendidikan dalam komunikasi antara Nabi Ibrahim dan Nabi Isma'il, yaitu aspek keimanan dan emosional. Keimanan kaitannya dengan uji kepatuhan terhadap konsep keimanan yang telah diberikan oleh Nabi Ibrahim, sedangkan aspek emosional ditunjukkan ketegaran dan kesabaran dalam menerima perintah tersebut.
\end{abstract}

Kata Kunci: Komunikasi, Orang tua, Anak, al-Qur'an. 


\begin{abstract}
Abstrak
Communication is the process of delivering a message in the form of meaningful symbols as thoughts and feelings in the form of ideas, information, beliefs, hopes, appeals, and as a guide by someone to someone else. Parents and children are the most important component in a family. Parents have an important role in educating their children through the communication process. The Qur'an as the first and main source of Islamic education provides some illustrations of the story of parent and child communication. One such story is the kisan of Prophet Ibrahim and Prophet Isma'il in Q.S. Al-Shä ffä $t$ verses 102-107. Based on the verses from the letter can be concluded communication parent and child (based on the story of Prophet Ibrahim and Prophet Ismail) as follows: 1) Communication happens is interactive-Dialogic-humanist communication. It is said interactional because the communication is not unilateral. Prophet Ibrahim and Prophet Isma'il are active, reflective in interpreting and interpreting the message in the dream of Abraham. Dialogical because the communication can open the path of information between Prophet Ibrahim and Prophet Ismail. Dialogic communication also helps to train arguments, patience, toughness, and perseverance to obey God and obey the parents, as happened in the communication of Prophet Ibrahim and Prophet Isma'il. Humanist because of Ibrahim's Education against Ishmael aims to humanize human beings to obey God; 2) Communication made Prophet Ibrahim with Prophet Isma'il gives an idea that the Prophet Ibrahim is a democratic figure and the Prophet Isma'il is a submissive figure. These two traits have an important role in the success of an education; 3) There are two educational materials in communication between Prophet Ibrahim and Prophet Isma'il, ie aspects of faith and emotional. Faith in relation to the test of obedience to the concept of faith that has been given by the Prophet Ibrahim, while the emotional aspect shown ketegaran and patience in receiving the command.
\end{abstract}

Kata Kunci: Communication, Parent, Kids, al-Qur'an.

\section{A. PENDAHULUAN}

Komunikasi merupakan hal yang tidak dapat dipisahkan dalam kehidupan seharihari manusia. Disadari atau tidak, setiap manusia yang berinteraksi dengan manusia lainnya maka dia telah melakukan proses komunikasi. Komunikasi tersebut terjadi dalam bentuk komunikasi verbal maupun non verbal. Komunikasi bisa terjadi dimanapun, lingkungan keluarga adalah salah satunya.

Keluarga memiliki dua komponen utama, yakni orang tua dan anak. Dalam tinjauan pedagogis, orang tua merupakan pendidik utama dan pertama bagi anakanak mereka. Dari orang tualah anak mula-mula menerima pendidikan. Orang tua mendidik anak-anaknya mulai dia lahir, bahkan hingga anak-anak dewasa pun orang tua masih berhak memberikan nasihatnya kepada anak sebagaimana ditegaskan dalam al-Qur'an surah an-Nisa' ayat 36 .

Al-Qur'an, sunnah adalah sumber utama agama Islam yang merupakan sebuah agama yang ajaran-ajarannya mulia, komprehensif dan universal. Ajaran-ajaran agama islam yang mulia tersebut ditransfer dan ditanamkan kepada anak melalui pendidikan yang diberikan di keluarga oleh orang tua. Dengan komunikasi yang harmonis antara 
orang tua dan anak, pendidikan dapat berlangsung dengan baik. Pendidikan umum dan agama. Utamanya pendidikan agama dimana Al-Qur'an dan sunnah sebagai sumber utamanya.

Terdapat banyak ayat al-Qur'an yang terdapat komunikasi di dalamnya. Salah satu proses komunikasi yang terdapat dalam al-Qur'an adalah komunikasi antara Nabi Ibrahim dan Nabi Isma'il, yang di dalamnya juga memiliki makna dan nilainilai dari proses komunikasi itu. Tujuan pembuatan tulisan ini adalah untuk menganalisis komunikasi antara antara Nabi Ibrahim dan Nabi Isma'il dalam tinjauan pedagogis.

\section{B. KAJIAN PUSTAKA}

a. Komunikasi

Kata komunikasi atau communication dalam bahasa Inggris berasl dari bahasa Latin communis yang berarti "sama", communico, communicatio, atau communicare yang berarti "membuat sama" (to make common). Istilah pertama (communis) adalah istilah yang paling sering sebagai asal usul komunikasi, yang merupakan akar dari kata-kata Latin lainnya yang mirip. Komunikasi menyarankan bahwa suatu pikiran, suatu makna, atau suatu pesan dianut secara sama. ${ }^{1}$

Komunikasi merupakan proses penyampaian suatu pesan dalam bentuk lambang bermakna sebagai pikiran dan perasaan berupa ide, informasi, kepercayaan, harapan, himbauan, dan sebagai panduan yang dilakukan oleh

\footnotetext{
${ }^{1}$ Deddy Mulyana, Ilmu Komunikasi Suatu Pengantar, vol. 2 (Bandung: Remaja Rosdakarya, 2000), 4.
}

seseorang kepada orang lain, baik langsung secara tatap muka maupun tidak langsung melalui media, dengan tujuan mengubah sikap, pandangan atau prilaku. ${ }^{2}$ Menurut komunikasi dilakukan dengan tujuan untuk perubahan sikap (attitude change), perubahan pendapat (opinion change), perubahan perilaku (behaviour change) dan perubahan sosial (social change). ${ }^{3}$

Komunikasi berfungsi untuk menyampaikan informasi (to inform), mendidik (to educate), menghibur (to entertain), dan mempengaruhi (to influence). Agar komunikasi efektif maka pesan dalam komunikasi harus berhasil menumbuhkan respon komunikan yang dituju berlangsung efektif, komunikator harus tahu khalayak mana yang akan dijadikan sasaran dan tujuan yang diinginkannya. Komunikator harus terampil dalam membuat pesan agar komunikan dapat menangkap pesan yang disampaikan komunikator dan untuk menciptakan komunikasi yang baik. ${ }^{4}$

Komunikasi merupakan suatu proses yang sangat mendasar dan vital dalam kehidupan manusia. Dikatakan mendasar karena setiap masyarakat manusia, baik yang primitif maupun yang modern, berkeinginan mempertahankan suatu persetujuan mengenai berbagai aturan sosial melalui komunikasi. Dikatakan vital karena setiap individu memiliki kemampuan untuk berkomunikasi dengan individu-individu

\footnotetext{
${ }^{2}$ Onong Uchjana Effendy, Dinamika Komunikasi, vol. 4 (Bandung: Remaja Rosdakarya, 2000), 60.

${ }^{3}$ Ibid., 4:8.

${ }^{4}$ Ibid.
} 
lainnya sehingga meningkatkan kesempatan individu itu untuk tetap hidup. $^{5}$

Jika dalam kacamata Islam, komunikasi yang baik adalah yang sesuai dengan etika Islam. Eika komunikasi dalam Islam dibagi menjadi dua, yaitu etika komunikasi transedental (hablum minallah) dan komunikasi insani (hablumminanas). Etika komunikasi transendental adalah suatu etika komunikasi yang berhubungan dengan sikap dan perilaku manusia ketika berkomunikasi dengan Allah SWT. Sedangkan etika komunikasi insani adalah etika komunikasi yang berhubungan dengan sikap dan perilaku manusia ketika berkomunikasi antar individu dan kelompok. $^{6}$

Etika komunikasi dalam Islam dibangun berdasarkan petunjuk al-Qur'an dan sunnah. Islam mengajarkan berkomunikasi itu dengan penuh adab, penuh penghormatan, penghargaan terhadap orang yang diajak bicara, dan sebagainya. Ketika berbicara dengan orang lain, Islam memberikan landasan yang jelas tentang tata cara berbicara. Tata cara berbicara kepada orang lain itu misalnya hanya membicarakan hal yang baik, menghindari perdebatan, menghindari pembicaraan dan permasalahan yang rumit, menyesuaikan diri dengan lawan bicara, tidak memuji

\footnotetext{
5 Jalaluddin Rakhmat, Psikologi Komunikasi (Bandung: Remaja Rosdakarya, 2001), 1.

${ }^{6}$ Syaiful Bahri Djamarah, Pola Komunikasi Orang Tua \& Anak Dalam Keluarga Sebuah Perspektfi Pendidikan Islam (Jakarta: PT Asdi Mahasatya, 2004), 103.
}

diri sendiri, dan tidak memuji orang lain dalam kebohongan. ${ }^{7}$

Terdapat enam prinsip etika komunikasi dalam Islam. Pertama, prinsip qawlan kariman atau perkataan yang mulia. Kedua, prinsip qawlan sadida atau perkataan yang benar dan lurus. Ketiga, prinsip qawlan ma'rufa atau perkataan yang baik. Keempat, prinsip qawlan baligha atau perkataan yang efektif/ keterbukaan. Kelima, qawlan layyina atau perkataan yang lemah lembut. Keenam qawlan maisura (perkataan yang pantas). ${ }^{8}$

Terdapat beberapa teori tentang pola komunikasi. Pola komunikasi di dalam keluarga seringkali berkisar seputar model stimulus-respon, model ABX dan model interaksional.

Pertama, model stimulus-respon (S-R) dianggap sebagai proses pertukaran atau pemindahan informasi atau gagasan. Proses ini bersifat imbal balik dan memiliki efek. ${ }^{9}$ Kedua, model ABX yaknimenggambarkan seseorang (A) menyampaikan informasi kepada seseorang lainnya (B) mengenai sesuatu (X). ${ }^{10}$ Ketiga, model interaksional menyatakan bahwa proses komunikasi digambarkan sebagai pembentukan makna., yakni penafsiran atas pesan atau perilaku orang lain oleh peserta komunikasi. ${ }^{11}$ Pada jenis komunikasi interaktif suasana dialogis lebih terbuka, yang aktif tidak hanya orang tua ke anak, akan tetapi juga anak ke orang tua.

\footnotetext{
${ }^{7}$ Ibid., 103-4.

${ }^{8}$ Ibid., 105.

${ }^{9}$ Mulyana, Ilmu Komunikasi Suatu Pengantar, 2:133.

${ }^{10}$ Ibid., 2:142.

${ }^{11}$ Ibid., 2:160.
} 
b. Kedudukan Orang Tua dalam Islam

Orang tua adalah pendidik dalam keluarga. Orang tua merupakan pendidik pertama dan utama bagi anak-anak mereka. Dari merekalah anak awal mulamula menerima pendidikan. Bentuk pertama dari suatu pendidikan terdapat dalam keluarga. ${ }^{12}$ Rasa cinta dan kasih sayang yang diberikan Allah kepada orangtua secara psikologis mampu membuat orang tua bersabar dalam memelihara, mengasuh, mendidik anak serta memperhatikan segala kemaslahatannya.

Orang tua memiliki tanggung jawab memelihara dirinya dan keluarganya agar selamat dari api neraka. Perintah yang antisipatif ini tertuang dalam salah satu firman-Nya:

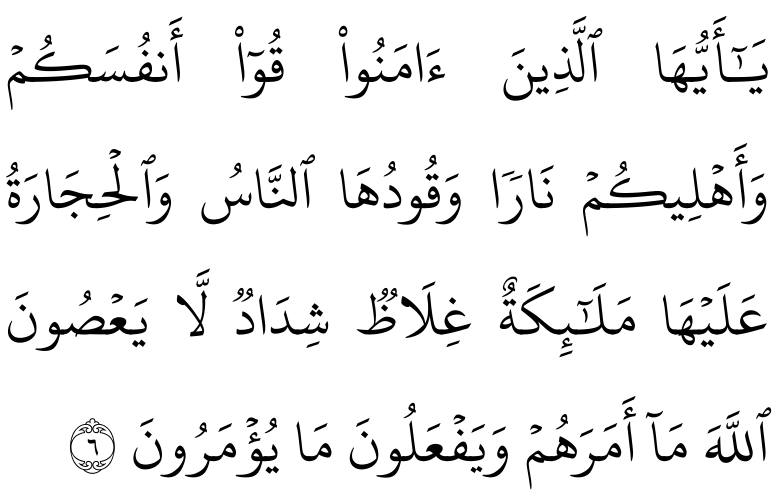

"Hai orang-orang yang beriman, peliharalah dirimu dan keluargamu dari api neraka yang bahan bakarnya adalah manusia dan batu; penjaganya malaikatmalaikat yang kasar, keras, dan tidak mendurhakai Allah terhadap apa yang diperintahkan-Nya kepada mereka dan

\footnotetext{
${ }^{12}$ Zakiah Daradjat, Ilmu Pendidikan Islam (Jakarta: Bumi Aksara, 1996), 20.
}

selalu mengerjakan apa yang diperintahkan."13

Tanggung jawab orang tua dalam mendidik anak-anaknya memang tidak ringan. Sikap orang tua harus mencerminkan akhlak mulia. Orang tua seharusnya memberikan contoh yang baik bagi anak dalam keluarga. Pembentukan budi pekerti adalah tujuan utama dalam pendidikan Islam. Karena dengan budi pekerti tersebutlah tercermin pribadi yang mulia. Sedangkan pribadi mulia itulah yang ingin dicapai dalam mendidik anak dalam keluarga.

c. Pendidikan Anak dalam al-Qur'an

Terdapat 4 macam kata dalam penyebutan anak pada al-Qur'an, al-awläd, al-banūn, al-athfäl dan ghilmān. Istilah alawläd dan al-banūn memiliki konotasi yang saling berlawanan. al-awläd berkonotasi makna negatif dan al-banūn memiliki konotasi positif, sehingga berimplikasi tersendiri dalam pendidikan anak. ${ }^{14}$

Pertama, istilah al-awlād, biasanya dikaitkan dengan makna yang pesimistis, sehingga anak memerlukan perhatian khusus dalam hal penjagaan, perhatian dan pendidikan. Maka janganlah harta benda dan anak-anak mereka menarik hatimu. Sesungguhnya Allah menghendaki dengan (memberi) harta benda dan anakanak itu untuk menyiksa mereka dalam kehidupan di dunia dan kelak akan melayang nyawa mereka, sedang mereka dalam keadaan kafir (Q.S. at-Taubah ayat

\footnotetext{
${ }^{13}$ Al-Qur'an Dan Terjemahnya (Jakarta: Departemen Agama RI, n.d.).

${ }^{14}$ Miftahul Huda dan Muhammad Idris, Nalar Pendidikan Anak, vol. 1 (Jogjakarta: Ar-Ruzz Media, n.d.), 76.
} 
55). Ayat lain menggambarkan anak yang menimbulkan fitnah, ${ }^{15}$ menjauhkan diri dari Allah, ${ }^{16}$ dan kesombongan pribadi. ${ }^{17}$

Ayat tersebut sebagai titik tolak untuk mencurahkan tenaga dan fikiran dalam rangka memperbaiki anak melalui proses pendidikan. Tujuannya adalah memperbaiki anak melalui proses pendidikan, sehingga mereka dapat menjadi wasilah untuk mendekatkan diri kepada Allah, bukan menjadi fitnah (bencana) bagi orang tua khususnya dan bagi masyarakat umumnya.

Kedua, ayat-ayat dengan ungkapan albanūn yang mengandung arti/pemahaman optimis. Sehingga menimbulkan kebanggan dan ketenteraman khusus dalam hati. ${ }^{18}$ Harta dan anak-anak adalah perhiasan kehidupan dunia tetapi amalanamalan yang kekal lagi saleh adalah lebih baik pahalanya di sisi Tuhanmu serta lebih baik untuk menjadi harapan. (Q.S. al-Kahfi ayat 55).

Berdasarkan ayat-ayat tentang alawlād dan al-banūn memiliki makna bahwa anak memiliki potensi menjadi impian yang menyenangkan jika dididik dengan baik, dan sebaliknya akan menjadi malapetaka (fitnah) jika tidak dididik dengan baik. Inilah kemungkinan yang ditimbulkan, yakni rasa optimis dan pesimis. Hal ini juga menunjukkan bahwa manusia dilahirkan dengan itrah dapat dididik dan juga mempunyai potensi tidak terdidik.

\footnotetext{
${ }^{15}$ Lihat Q.S. al-Anfal ayat 28

${ }^{16}$ Lihat Q.S. an-Naba' ayat 37

${ }^{17}$ Lihat Q.S. al-Hadid ayat 20

${ }^{18}$ Lihat Q.S. al-Hadid ayat 20
}

Ketiga, istilah al-athfäl, menandakan anak-anak yang telah memasuki masa baligh perlu diperlakukan secara manusiawi dalam memasuki masanya (Q.S. al-Nūr ayat 59). Ayat lain menjelaskan periodesasi yang dialami dalam penciptaan dan kehidupan manusia. ${ }^{19}$ Selain itu juga digunakan untuk menjelaskan anak-anak yang belum mengerti aurat wanita (sehingga memandang anak-anak tidak termasuk aurat).

Keempat, istilah ghilmān menggambarkan anak-anak muda yang melayani di Syurga. (Q.S. al-Thūr ayat 24). Pemaknaan ghilmān berkonotasi makna anugerahyang luar biasa berupa keturunan (anak) di luar batas perhitungan manusia hal ini sebagaimana terjadi dalam keluarga Nabi Zakaria yang mendapat keturunan Yahya pada saat usianya senja dan bahkan isterinya pun dalam keadaan mandul. ${ }^{20}$ Demikian juga yang terjadi pada Maryam yang mendapat keturunan Nabi Isa tanpa perantara seorang laki-laki. ${ }^{21}$ Ghilmān juga berkonotasi makna anak yang menakjubkan (kisah Nabi Yusuf dalam Q.S. Yusuf ayat 19 ), anak laki-laki yang alim (sebutan untuk Nabi Ishaq dalam Q.S. alHijr: 53, Q.S. al-Dzāriyāt ayat 28), anak lakilaki yang amat sabar (sebutan untuk Nabi Isma'il dalam Q.S. al-Shāffāt ayat 101), dan anak laki-laki yang keturunan orang mukmin (Q.S. al-Kahfi ayat 80-82).

Berdasarkan empat istilah anak dalam al-Qur'an tersebut dapat

\footnotetext{
${ }^{19}$ Q.S. al-Hajj ayat 20, Q.S. al-Ghafir ayat 67.

${ }^{20}$ Q.S. Maryam ayat 7, Q.S. al-Imran ayat 40

${ }^{21}$ Q.S. Maryam ayat 20.
} 
disimpulkan bawa anak memiliki makna pesimistis dan optimistis. Pendidikan adalah salah satu jalan bagaimana menghilangkan makna pesimistis pada anak dan hanya menumbuhkan makna optimistis dari anak. Dan orang tua memiliki posisi pertama dan utama dalam proses pendidikan bagi anak.

\section{METODE PENELITIAN}

Penelitian ini merupakan penelitian kualitatif. Penelitian kualitatif adalah Lexy J.Moleong yang mengutip pendapat Bogdan Taylor bahwa penelitian kualitatif adalah prosedur penelitian yang menghasilkan data deskriptif berupa kata-kata tertulis atau lisan dari orang-orang dan perilaku yang dapat diamati. ${ }^{22}$

Terdapat beberapa jenis penelitian kualitatif. Jenis penelitian kualitatif yang digunakan di penelitian ini adalah studi kepustakaan (Library research). Studi kepustakaan adalah Studi teks penelitian yang dilaksanakan dengan menggunakan literatur (kepustakaan), baik berupa buku, catatan, maupun laporan hasil penelitian dari penelitian terdahulu. ${ }^{23}$

Sumber data dalam penelitian ini berasal dari berbagai literatur kepustakaan. Literatur kepustakaan yang digunakan adalah yang memiliki kaitan dengan komunikasi, pendidikan orang tua kepada anak maupun pendidikan anak dalam al-Qur'an.

\footnotetext{
${ }^{22}$ Meleong J. Lexy and Others, Metodologi Penelitian Kualitatif (Yogyakarta: Remaja Rosdakarya, 1996). ${ }^{23}$ Ibid., 6.
}

Teknik pengumpulan data dalam penelitian ini adalah teknik dokumentasi. Teknik dokumentasi adala cara mengumpulkan data dari sumber yang berupa catatan, transkrip, buku, surat kabar, majalah, prasasti, notulen rapat, dan sebagainya yang diperoleh baik dari sumber primer maupun sekunder. ${ }^{24}$ Data-data yang diperoleh dianalisis dengan menggunakan analisis isi (content analysis) yaitu teknik sistematis yang digunakan untuk menganalisis isi pesan, mengolah pesan, atau untuk mengobservasi dan menganalisis perilaku komunikasi. ${ }^{25}$

\section{HASIL PENELITIAN}

Proses komunikasi antara orang tua dan anak yang tercermin dalam alQur'an sangat banyak. Masing-masing dari komunikasi tersebut memiliki bentuk, tujuan, nilai, makna dan materi yang berbeda-beda. Berikut akan dipaparkan tentang salah satu bentuk komunikasi orang tua dan anak yang tergambar dari komunikasi antara Nabi Ibrahim dan Nabi Isma'il.

Nama Ibrahim disebut dalam alQur'an sebanyak 69 kali pada 63 ayat dan menjadi nama Surah ke 14. Sedangkan Nabi Isma'il disebut sebanyak 12 kali pada 12 ayat. Adapun ayat-ayat yang memuat interaksi pendidikan Ibrahim dengan Isma'il terdapat dalam peristiwa

\footnotetext{
${ }^{24}$ Nana Syaodih Sukmadinata, Metode Penelitian Pendidikan (Bandung: Remaja Rosdakarya, 2009), 21-22.

${ }^{25}$ Amirul Hadi and Haryono, Metodologi Penelitian Pendidikan (Bandung: Pustaka Setia, 1998), 175.
} 
penyembelihan pada Q.S. al-Shāffāt ayat 102-107. ${ }^{26}$

a. Komunikasi Nabi Ibrahim dan Nabi Isma'il dalam Al-Qur'an dan Tafsirannya

Komunikasi yang terjadi antara Nabi Ibrahim dan Nabi Isma'il terdapat dalam Q.S. al-Shāffāt ayat 102-107. Ayat tersebut secara kronologis memuat penjelasan tentang mimpi Nabi Ibrahim menyembelih Nabi Isma'il. Nabi Ibrahim mendialogkan mimpinya dengan Nabi Isma'il, pelaksanaan penyembelihan dan diakhiri dengan keselamatan Isma'il. ${ }^{27}$

Berikut terjemahan dari Q.S. alShāffāt ayat 102, "Maka tatkala anak itu sampai (pada umur sanggup) berusaha bersama-sama Ibrahim, Ibrahim berkata: "Hai anakku Sesungguhnya Aku melihat dalam mimpi bahwa Aku menyembelihmu. Maka fikirkanlah apa pendapatmu!" ia menjawab: "Hai bapakku, kerjakanlah apa yang diperintahkan kepadamu; insya Allah kamu akan mendapatiku termasuk orangorang yang sabar".

Penafsiran kata "Maka tatkala anak itu sampai (pada umur sanggup) berusaha bersama-sama Ibrahim". Maksudnya adalah ketika Nabi Isma'il tumbuh dewasa dan mau bepergian dengan Nabi Ibrahim, maka Nabi Ibrahim senantiasa mengawasi ke mana saja dia pergi di daerah Faran. Nabi Ibrahim juga memberikan perhatian penuh terhadap permasalahan yang dihadapinya. Menurut riwayat Ibn 'Abbas bahwa mimpi para Nabi termasuk wahyu.

\footnotetext{
${ }^{26}$ Huda and Idris, Nalar Pendidikan Anak, 1:146-47.

${ }^{27}$ Ibid., 1:148.
}

Pada ayat ini, Nabi Ibrahim memberitahu Nabi Isma'il tentang mimpinya agar dapat dipahami oleh Nabi Isma'il yang masih kecil. Selain untuk melatih kesabaran, ketangguhan, dan keteguhannya untuk patu kepada Allah dan taat kepada orang tua. Menurut al-Farra', usia Nabi Isma'il pada saat itu adalah 13 tahun. Sedangkan menurut Ibn Abbas adalah menginjak usia pubertas (ihtilam).28

Ibrahim berkata: "Hai anakku Sesungguhnya Aku melihat dalam mimpi bahwa Aku menyembelihmu. Maka fikirkanlah apa pendapatmu!". Menurut Muqatil, mimpi Nabi Ibrahim menyembelih Isma'il itu terjadi selama 3 malam berturut-turut. Tentang mimpi ini, menurut Ka'ab Ahbar, wahyu Allah datang kepada para rasul dalam keadaan terjaga dan tertidur. Karena para nabi meskipun tidur pada dasarnya hatinya tidak tidur. ${ }^{29}$

Ia menjawab: "Hai bapakku, kerjakanlah apa yang diperintahkan kepadamu; insya Allah kamu akan mendapatiku termasuk orang-orang yang sabar". Menurut al-Suyuthi pasrah dan patuh merupakan cerminan dari sabar tingkat tinggi. ${ }^{30}$ Menurut Qutb mimpi untuk menyembelih Nabi Isma'il hanya merupakan isyarat bukan merupakan perintahyang sifatnya langsung dan jelas (sharih). Meskipun demikian, Nabi Ibrahim menerimanya tanpa banyak bertanya, kenapa Allah memberikan

\footnotetext{
${ }^{28}$ Abi Abd Allah Muhammad bin Ahmad al-Anshari al-Qurthubi, Al-Jami' Li Al-Ahkam Al-Qur'an, vol. 15 (Beirut: Dar Fikr, 1988), 99.

${ }^{29}$ Ibid., 15:102.

${ }^{30}$ Abd Al-Rahman bin Kamal Jalal al-Din al-Suyuthi, Al-Durr Al-Manthur I Tafsir Al-Ma'tsur, vol. 7 (Beirut: Dar Fikr, tt.), 109.
} 
perintah untuk menyembelih anak satusatunya. Penerimaan Nabi Ibrahim atas perintah Allah ini dengan penuh kerelaan sepenuh hati. 31

Terjemahan selanjutnya, Q.S. al- alShāffāt ayat 103 yang artinya "Tatkala keduanya Telah berserah diri dan Ibrahim membaringkan anaknya atas pelipis(nya), (nyatalah kesabaran keduanya)."

"Tatkala keduanya Telah berserah diri" maknanya Nabi Ibrahim dan Nabi Isma'il telah menyerahkan diri kepada Allah, dan keduanya sepakat untuk melaksanakan perintah Allah. ${ }^{32}$ Keduanya percaya diri, taat, ridha dan pasrah terhadap perintah. Hal ini bukan berarti semangat dan keberanian belaka bagaikan perjuangan ke medan perang yang mungkin hidup ataupun bahkan mati. Akan tetapi, itu semua merupakan wujud kepasrahan murni dari kesadaran hati yang tulus dengan penuh tenang dan ridha dengan merasakan nikmatnya ketaatan. ${ }^{33}$

\section{Dan Ibrahim membaringkan} anaknya atas pelipis (nya), (nyatalah kesabaran keduanya ). Menurut Mujahid, Isma'il (ketika akan disembelih) dalam keadaan sujud. ${ }^{34}$

Terjemahan selanjutnya, Q.S. al- alShäffăt ayat 104 dan 105 yang artinya 104. Dan kami panggillah dia: "Hai Ibrahim,

\footnotetext{
${ }^{31}$ Ibnu Kathir al-Dimashqi, Tafsiir Al-Qur'an Al-Azim (Beirut: Dar al-Kutub al-Ilmiyyah., n.d.), 15.

32 al-Suyuthi, Al-Durr Al-Manthur I Tafsir Al-Ma'tsur, $7: 111$.

${ }^{33}$ Sayyid Qutb, Fi Dhilal Al-Qur'an (Turath: Dar Ihya', tt.), 64.

${ }^{34}$ al-Suyuthi, Al-Durr Al-Manthur I Tafsir Al-Ma'tsur, $7: 111$.
}

Sesungguhnya kamu Telah membenarkan mimpi itu ${ }^{35}$ Sesungguhnya Demikianlah kami memberi balasan kepada orangorang yang berbuat baik. Tafsiran dari Dan kami panggillah dia: "Hai Ibrahim, Sesungguhnya kamu Telah membenarkan mimpi itu, yakni dengan melaksanakan apa yang diperintahkan Allah, Dia tidak menghendaki kecuali kepasrahan dan kepatuhan. ${ }^{36}$ Sedangkan tafsiran dari Sesungguhnya Demikianlah kami memberi balasan kepada orang-orang yang berbuat baik adalah Allah membalas mereka yang melakukan kebenaran dengan sepenuh hati. Mereka diangkat derajadnya, karena ketangguhan dan kesabarannya menghadapi cobaan. ${ }^{37}$

Terjemahan ayat selanjutnya Q.S. al-Shāffāt ayat 106, Sesungguhnya Ini benar-benar suatu ujian yang nyata. Maksudnya ujian (bala') yang tidak disenangi (makruh) yaitu harus menyembelih anaknya. ${ }^{38}$

Terjemahan terakhir ayat tentang komuniasi, Nabi Ibrahim dan Nabi Isma'il. Terjemahan Q.S. al-Shāffāt ayat 107, Dan kami tebus anak itu dengan seekor sembelihan yang besar. ${ }^{39}$ Maknanya ketika Nabi Ibrahim telah yakin untuk melaksanakan perintah wajib

\footnotetext{
${ }^{35}$ yang dimaksud dengan membenarkan mimpi ialah mempercayai bahwa mimpi itu benar dari Allah s.w.t. dan wajib melaksana- kannya

${ }^{36}$ Qutb, Fi Dhilal Al-Qur'an, 65.

${ }^{37}$ Ibid.

38 al-Qurthubi, Al-Jami' Li Al-Ahkam Al-Qur'an, 15:107.

${ }^{39}$ Sesudah nyata kesabaran dan ketaatan Ibrahim dan Ismail a.s. Maka Allah melarang menyembelih Ismail dan untuk meneruskan korban, Allah menggantinya dengan seekor sembelihan (kambing). peristiwa Ini menjadi dasar disyariatkannya qurban yang dilakukan pada hari raya haji.
} 
meneymbelih Isma'il, dan dalam keadaan siap menyembelih, maka sebelum pisau dihujamkan ke leher Isma'il, Allah menggantinya dengan kibas. ${ }^{40}$

b. Bentuk dan Nilai-Nilai Komunikasi Nabi Ibrahim dan Nabi Isma'il

Berdasarkan Q.S. al-Shāffāt ayat 102-107 dapat disimpulkan bahwa komunikasi yang tampak dari kisah Nabi Ibrahim dan Nabi Isma'il adalah model komukasi interaksional. Karena komunikasi yang dilakukan tidak sepihak. Nabi Ibrahim dan Nabi Isma'il saling aktif, reflektif dalam memaknai dan menafsirkan pesan dalam mimpi Nabi Ibrahim.

Selain interaksional, komunikasi yang dilakukan Nabi Ibrahim dan Nabi Isma'il juga dialogis. Nabi Ibrahim memberitahu Nabi Isma'il tentang mimpinya agar dapat dipahami oleh Nabi Isma'il.

Komunikasi dialogis dapat membuka jalur informasi antara orang tua dan anak. Orang tua dapat mengetahui kemampuan anak melalui dialog. Dengan dialog, akan ditemukan persamaan visi dan misi pendidikan yang akan dilakukan. Komunikasi dialogis membangun interaksi antara orang tua dan anak menjadi harmonis. Menurut Ibn Katsir, cara dialog juga untuk melatih berargumentasi, kesabaran, ketangguhan, dan keteguhan untuk patuh kepada Allah dan taat pada orang tua. ${ }^{41}$

\footnotetext{
${ }^{40}$ al-Qurthubi, Al-Jami' Li Al-Ahkam Al-Qur'an, 15:105.

${ }^{41}$ al-Dimashqi, Tafsiir Al-Qur'an Al-Azim, 15.
}

Pendidikan Ibrahim terhadap Ismail bertujuan untuk memanusiakan manusia agar patuh kepada Allah. Pendidikan humanis ini berisi nilai-nilai keutamaan atau kebajikan yang dapat mengangkat kemuliaan manusia. Dalam konteks humanisasi, Nabi Ibrahim mengajarkan kepada Nabi Isma'il bagaiman membangun harkat dan martabat manusia di sisi Allah. Tujuan ini direalisasikan dengan membangun citra manusia yang taat kepada nilai-nilai kemanusiaan yang diperintahkan oleh Allah. ${ }^{42}$

Berdasarkan komunikasi Nabi Ibrahim dan Nabi Isma'il dalam Q.S. alShāffāt ayat 102-107 dapat kita lihat pula bahwa Nabi Ibrahim adalah sosok yang demokratis. Untuk tugas berat mengenai wahyu Allah melalui mimpi ${ }^{43}$ untuk menyembelih Isma'il, Nabi Ibrahim berusaha memahami kejiwaan Isma'il tentang bagaimana kesanggupannya menjalankan perintah Allah. Demrokatisasi Nabi Ibrahim dalam mendidik Isma'il merupakan kearifan orang tua dalam mendidik anak-anaknya.

Sikap demokratis yang ditunjukkan Nabi Ibrahim berujung kepatuhan dari Isma'il. Kebebasan memilih yang ditawarkan Nabi Ibrahim membuat Nabi Isma'il justru dengan bangga dan patuh mempersilahkan Nabi Ibrahim melaksanakan perintah tersebut.

\footnotetext{
${ }^{42}$ Huda and Idris, Nalar Pendidikan Anak, 1:153.

${ }^{43}$ Mimpi Nabi Ibrahim menyembelih Nabi Isma'il terjadi selama tiga malam berturut-turut. Memang demikian wahyu Allah datang kepada para rasul dalam keadaan tidur, bahkan dalam keadaan terjaga. Para nabi meskipun tidur pada dasarnya hatinya tidak tidur. al-Qurthubi, Al-Jami' Li Al-Ahkam Al-Qur'an, 15:102.
} 
Terdapat dua materi pendidikan dalam komunikasi antara Nabi Ibrahim dan Nabi Isma'il, yaitu aspek keimanan dan emosional. Pada aspek keimanan secara implisit merupakan uji kepatuhan terhadap konsep keimanan yang telah diberikan oleh Nabi Ibrahim, yang merupakan perintah Allah, meskipun nyawa menjadi taruhannya. Pada aspek emosional ditunjukkan ketegaran dan kesabaran dalam menerima perintah tersebut. Dan perintah Allah tersebut berujung sikap Nabi Isma'il yang menunjukkan dedikasi tinggi dengan loyalitas kesiapan emosionalnya, sehingga lulus dari kematian. ${ }^{44}$

\section{E. KESIMPULAN}

Komunikasi antara Nabi Ibrahim dengan Nabi Isma'il terdapar pada Q.S. alShāffāt ayat 102 - 107. Berdasarkan ayat tersebut dapat ditarik kesimpulan bahwasannya komunikasi yang dilakukan Nabi Ibrahim dengan Nabi Isma'il adalah komunikasi interaksional-dialogishumanis. Dikatakan interaksional karena komunikasi yang dilakukan tidak sepihak. Nabi Ibrahim dan Nabi Isma'il saling aktif, reflektif dalam memaknai dan menafsirkan pesan dalam mimpi Nabi Ibrahim. Dialogis karena komunikasi tersebut dapat membuka jalur informasi antara Nabi Ibrahim dan Nabi Ismail. Komunikasi dialogis juga membantu untuk melatih berargumentasi, kesabaran, ketangguhan, dan keteguhan untuk patuh kepada Allah dan taat pada orang tua, seperti yang terjadi pada komunikasi Nabi Ibrahim dan Nabi Ismail. Humanis karena

\footnotetext{
${ }^{44}$ Huda and Idris, Nalar Pendidikan Anak, 1:153.
}

Pendidikan Ibrahim terhadap Ismail bertujuan untuk memanusiakan manusia agar patuh kepada Allah.

Nabi Ibrahim adalah sosok yang demokratis. Nabi Ibrahim berusaha memahami kejiwaan Isma'il tentang bagaimana kesanggupannya menjalankan perintah Allah. Nabi Ibrahim dalam mendidik Isma'il merupakan kearifan orang tua dalam mendidik anak-anaknya.

Terdapat dua materi pendidikan dalam komunikasi antara Nabi Ibrahim dan Nabi Isma'il, yaitu aspek keimanan dan emosional.

\section{F. DAFTAR PUSTAKA}

Al-Qur'an Dan Terjemahnya. Jakarta:

Departemen Agama RI, n.d.

Daradjat, Zakiah. Ilmu Pendidikan Islam.

Jakarta: Bumi Aksara, 1996.

Dimashqi, Ibnu Kathir al-. Tafsiir Al-Qur'an

Al-Azim. Beirut: Dar al-Kutub al-

Ilmiyyah., n.d.

Djamarah, Syaiful Bahri. Pola Komunikasi

Orang Tua \& Anak Dalam Keluarga

Sebuah Perspektif Pendidikan Islam.

Jakarta: PT Asdi Mahasatya, 2004.

Effendy, Onong Uchjana. Dinamika

Komunikasi. Vol. 4. Bandung:

Remaja Rosdakarya, 2000.

Hadi, Amirul, and Haryono. Metodologi

Penelitian Pendidikan. Bandung:

Pustaka Setia, 1998.

Huda, Miftahul, and Muhammad Idris.

Nalar Pendidikan Anak. Vol. 1.

Jogjakarta: Ar-Ruzz Media, 2008.

Meleong J. Lexy, and Others. Metodologi

Penelitian Kualitatif. Yogyakarta:

Remaja Rosdakarya, 1996. 
Mulyana, Deddy. Ilmu Komunikasi Suatu

Pengantar. Vol. 2. Bandung: Remaja

Rosdakarya, 2000.

Qurthubi, Abi Abd Allah Muhammad bin

Ahmad al-Anshari al-. Al-Jami' Li Al-

Ahkam Al-Qur'an. Vol. 15. Beirut:

Dar Fikr, 1988.

Qutb, Sayyid. Fi Dhilal Al-Qur'an. Turath:

Dar Ihya', tt.

Rakhmat, Jalaluddin. Psikologi Komunikasi.

Bandung: Remaja Rosdakarya,

2001.

Sukmadinata, Nana Syaodih. Metode

Penelitian Pendidikan. Bandung:

Remaja Rosdakarya, 2009.

Suyuthi, Abd Al-Rahman bin Kamal Jalal al-

Din al-. Al-Durr Al-Manthur I Tafsir

Al-Ma'tsur. Vol. 7. Beirut: Dar Fikr,

$\mathrm{tt}$. 